\title{
Traditional and Flipped Learning: Which Enhances Students' Academic Performance Better?
}

\author{
J. R. Sablan and M. Prudente
}

\begin{abstract}
Most of the learning institutions even before the global pandemic are using a blended learning strategy. One of the most promising and leading blended-strategy today is the Flipped Classroom Model (FCM). FCM, often called as inverted classroom or reversed instruction, is a teaching model where the content of the study is given outside the classroom and homework is done inside the classroom. Previous researches yields different results when FCM is compared with traditional learning in enhancing students' academic performance. To address the problem, a meta-analysis has been conducted. In this study, 15 articles were chosen to be meta-analyzed. The researchers used the PRISMA model in conducting the meta-analysis and the Meta-essentials for data analysis. The analysis yields a p-value of 0.000 which means that there is a statistical significant effect by the intervention FCM to the academic performance of the students. The hedges' $g$ value of 0.93 has a verbal interpretation of large effect. Through subgroup analysis, it was found that FCM has a positive effect on the academic performance of the students in the subjects Physics and Mathematics with a $p$ value of 0.000 . This is also true in the subgroup, Geographical Location (Eastern and Western Countries), that yields a p-value of 0.000 . Further, a moderator analysis on class size and intervention duration was also conducted. A significant p-value was found on the moderator implementation duration but not significant in the moderator class size. The analysis favors the longitudinal use of Flipped Classroom Model on enhancing student's academic performance over Traditional Lecture Model in the subjects Physics and Mathematics regardless the class size of the students and the regions where the studies were conducted.
\end{abstract}

Index Terms-Academic achievement, flipped classroom, meta-analysis, traditional lecture.

\section{INTRODUCTION}

Most of the learning institutions even before the global pandemic are using a blended-learning strategy that combines face-to-face classes with online learning to facilitate teaching and learning processes [1]. One of the most promising and leading blended strategy is the Flipped Classroom Model (FCM) and it has gain popularity over the decades [2], [3]. FCM is a blended learning strategy, often called as inverted classroom or reversed instruction, where the content of the study is given outside the classroom and homework is done inside the classroom [4].

In the experiment conducted by [5], students' overall engagement in mathematics class was improved by the

Manuscript received June 25, 2021; revised August 11, 2021.

J. R. Sablan is with College of Arts and Science, Rizal Technological University, Mandaluyong City, Philippines (e-mail: jack_sablan@dlsu.edu.ph).

M. Prudente is with Science Education Department, De La Salle University, Manila, Philippines (e-mail: aricar.prudente@dlsu.edu.ph). flipped classroom model. Students also showed sense of responsibility with their own learning during the implementation of FCM [6]. Barkley [2] found out that flipped classroom model enhanced student learning because students are given individualized supervision by the teacher. It also facilitates interaction among the students that leads to better learning results [7].

Not only conceptual learning is enhanced by the FCM but also students' emotions and perceptions toward it. According to the study conducted [8], students have a positive emotions and perceptions towards flipped classroom model. Students are enjoying in this model while learning and this can lead to a positive outcome of students' learning. When it comes to the applicability of the FCM, Deri and Mills et al. [9] discovered in their study that FCM is feasible to students with different demographic profiles, academic achievement and class size.

The result on how well FC enhances students' self-regulation and academic performance is inconclusive. Studies by Astra and Khumaeroh [10] and Zandra et al. [11] found significant improvement in the academic achievement of their students when compared to the traditional lecture. On the other hand, studies conducted by [12]-[14] found no difference in the academic performance of students in FC when compared to the traditional lecture. This is something that needs to be explored in further researches.

While it is true that the use of FCM improves students' engagement and positive emotion towards learning, it is still undecided if the FCM enhances students' academic achievement. When compared to the traditional lecture, numbers of researches have been conducted on the effectiveness of the two intervention. The purpose of this study is to conduct a comprehensive meta-analysis of the comparison between the use of traditional lecture and the Flipped Classroom Model (FCM) focusing on the teaching of Physics and Mathematics.

\section{A. Statement of the Problem}

To deeply examine the effectiveness of a Flipped Classroom Model of teaching in the tertiary level Physics, the following research questions were used as a guide in presenting and analyzing the results:

1) Which teaching method improves students' academic performance better: Flipped Classroom Model (FCM) or Traditional Lecture?

2) What are the moderators that affect the effectiveness of FCM?

3) Is there a statistically significant difference in the academic performance of the two interventions when grouped into the following sub-groups:

- Subject Matter 


\section{- Geographical Location}

\section{B. Conceptual Framework}

This meta-analysis focused on the improvement of the academic performance of college and high school students in Physics and Math which is measured through the test of cognitive skills in examinations. It focused on the concept of cognitive learning that is defined as process of quantifying students' intellectual effort as a result of the learning process [15].

To further differentiate and test the effectiveness of FCM, class size and implementation duration was set as the moderator variable of the study and subject matter and geographical location where the study was conducted was set as the subgroups.

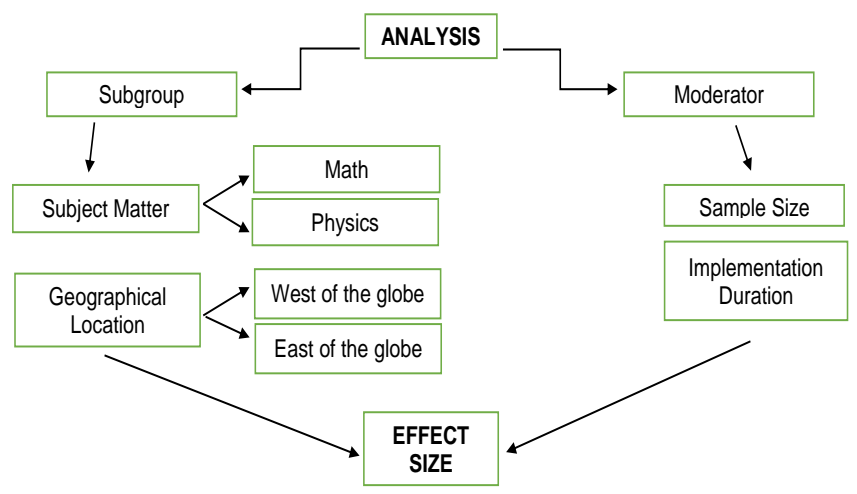

Fig. 1. Conceptual framework.

Fig. 1 shows the conceptual framework of the study. Two analyses were conducted based on the effect sizes of the articles included these are subgroup analysis and moderator analysis. Subgroup analysis is conducted to subject matter, Physics and Mathematics, and geographical location, eastern or western region, while moderator analysis is conducted to sample size and implementation duration which are both considered as continuous data.

\section{MethodOlOGY}

\section{A. Data Sources and Search Strategies}

This meta-analysis uses the PRISMA (Preferred Reporting Items for Systematic reviews and Meta-Analysis) guidelines on identifying eligible researches in a comprehensive way [16]. There are three (3) databases that were searched namely, Google Scholar, Scopus, and CrossRef. This was done elegantly with the use of the software Harzing's Publish or Perish [17]. Results were saved as an EndNote file so that it can be analyzed further using another software which is the EndNote App.

Using various numbers of techniques in using metasearch engine, articles were trimmed down into a workable number having common denominator.

Keywords like "Effect", "Physics", "Flipped", "Traditional", and "Performance" were used to trim down the numbers of articles searched in the databases. Further, the present study uses a list of pre-set eligibility criteria to specifically choose the most eligible and data extractible articles.

\section{B. Eligibility Criteria}

Inclusion and exclusion criteria for this analysis are as follow:

1) The studies must contain a result of comparison between the performance of the students in a flipped classroom model and in a traditional classroom focusing on subjects with problem solving skills like mathematics and physics subjects.

2) The flipped classroom model must contain classroom activities and pre-recorded videos personally created by the instructor or adopted from other lecturer.

3) In this meta-analysis, the researcher only included studies that view flipped classroom model as a blended learning strategy that includes students going to class to do activities and listening to content videos prior to the classroom discussion.

4) Traditional classroom pertains to the type of strategy that students go to the classroom during class hours, listen to the lecture of the teacher and do homework outside the class.

5) The studies must use the two groups of quasi-experimental or experimental research design.

6) The studies must use the same objective type of assessment given to the traditional and flipped classroom model in a form of pre and posttest.

7) There is no restrictions in location but articles must be written in the English and published and reviewed by professionals.

After using the keywords, "Effect", "Physics", "Flipped", "Traditional", and "Performance", the total number of studies gathered using three databases is 1200 . The largest number comes from Google Scholar which is 999, 200 of it comes from CrossRef and 1 from Scopus. After looking for duplicate articles, 1 study was removed. It was then analyzed using the software EndNote to further check the content of the articles in terms of the title, abstract and any other field. There are 1174 articles removed because of not containing the keywords from the title and abstract. The remaining 32 studies were then fully read by the researcher to check if it matches the eligibility criteria set in the start of the study. Only 11 articles were then included in the analysis after checking for eligibility.

Fig. 2 shows a comprehensive procedure undertaken by the researcher in the identification of eligible studies for analysis. This follows the PRISMA (Preferred Reporting Items for Systematic reviews and Meta-Analysis) guidelines.

\section{Data Analysis}

Meta-essentials v.1.5 was used to analyze all the data extracted from the 15 articles [18]. The mean of the posttest scores of the students were calculated for the effect sizes. A two-sided $p$ value below 0.05 was regarded as significant for all analyses.

There are two commonly used statistical models in meta-analysis and these are the fixed-effects and the random-effects. According to [19], random effects was used if there is no heterogeneity in the pool of data. If the data collected are heterogeneous it will be detected by the $\mathrm{I} 2$ test. Data are considered heterogeneous if the $p$-value of Cochran's Q statistic is $<0.1$. 
Another area of analysis is the publication bias. It happens when the researcher only chose to include publications with favorable results [20]. And lastly, moderator variables like subject matter, year of publication, and sample size where analyzed to examine if they influence the results of the study conducted.

Two analyses were conducted based on the effect sizes of the articles included these are subgroup analysis and moderator analysis. Subgroup analysis is conducted to subject matter, Physics and Mathematics, and geographical location, eastern or western region, while moderator analysis is conducted to sample size and implementation duration which are both considered as continuous data.

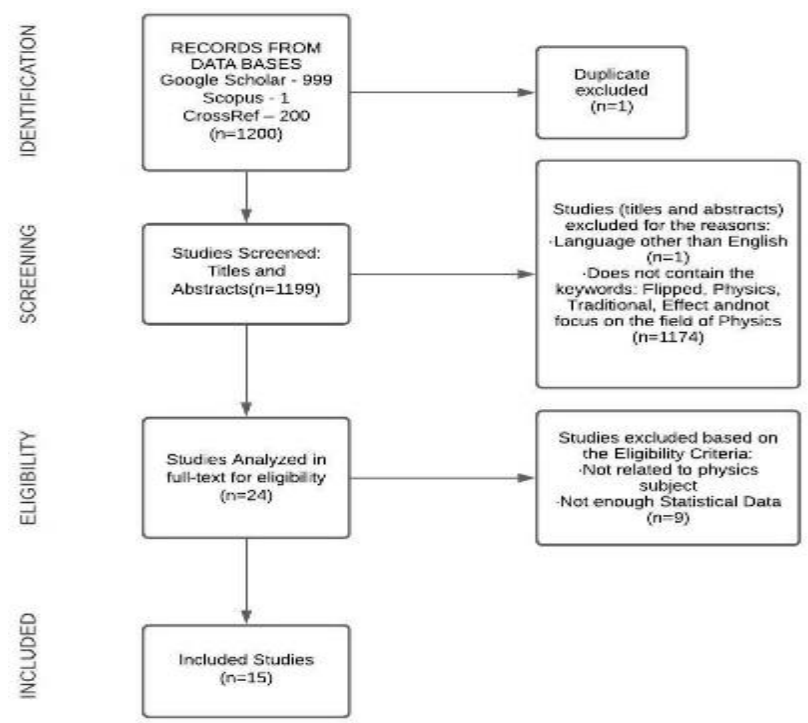

Fig. 2. Selection process.

\section{RESULTS AND DISCUSSIONS}

\section{A. Characteristics of the Studies Included}

There are 15 articles included in this meta-analysis review [10], [12]-[14], [21]-[31]. These articles were published from 2017 to 2020, and all of the studies used either experimental or quasi-experimental designs that compares Flipped Classroom Model and Traditional Lecture. The sample sizes ranged from 30 to 200 participants, and the total sample size was 2150 (experimental group $=1037$ and control group=1113).

\section{B. Effect Size}

TABLE I: Z VALUES AND P VALUES OF EFFECT SIZE

\begin{tabular}{|c|c|}
\hline \multicolumn{2}{|c|}{ Combined Effect Size } \\
\hline Hedges' g & 0.93 \\
\hline Standard error & 0.24 \\
\hline CI Lower limit & 0.41 \\
\hline CI Upper limit & 1.45 \\
\hline PI Lower limit & -0.68 \\
\hline PI Upper limit & 2.55 \\
\hline & \\
\hline Z-value & 3.84 \\
\hline One-tailed p-value & 0.000 \\
\hline Two-tailed p-value & 0.000 \\
\hline
\end{tabular}

After extracting the necessary data from the articles included in the study, the analysis was done using the
Meta-essentials v.1.5 which were developed by [18]. Table I shows the p-value and the z-value of the Forest plot which will tell us if there is a statistically significant effect by the intervention we are testing and the academic performance of the students. On the other hand, p-values cannot tell us up to what extent is the effect of the intervention so Fig. 3 shows a pictorial representation of the Forest Plot.

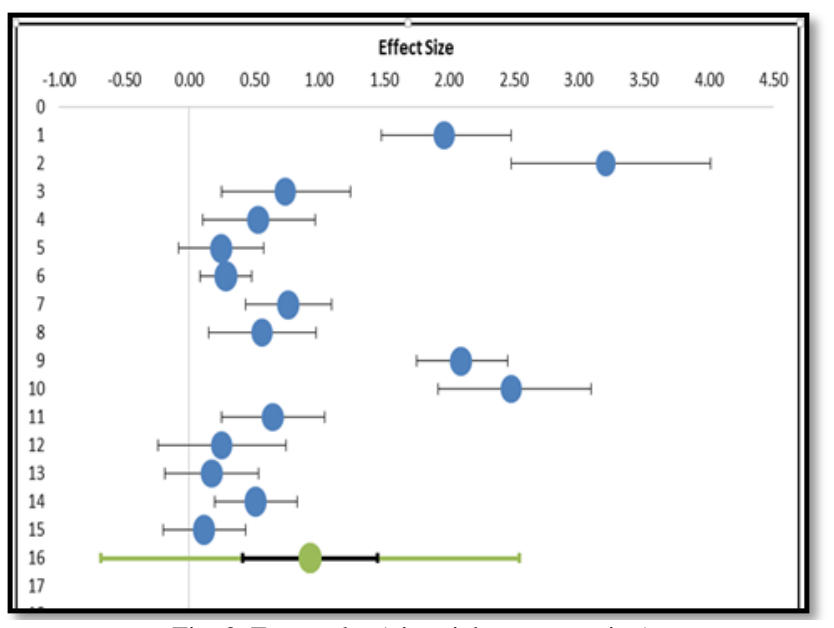

Fig. 3. Forest plot (pictorial representation).

The computed p-value as seen in Table I is 0.000 which is less than 0.005 and it means that we have to reject the null hypothesis and report that there is a statistically significant difference or effect on the comparison of the Flipped Classroom Model and the Traditional Lecture model. The overall value of

Hedges' $g$ is 0.93 that can be interpreted that the intervention FCM has a high effect on the academic performance of the students.

\section{Test of Heterogeneity}

Table II shows the heterogeneity test of the 15 articles included in this meta-analysis. As seen in the table, it has a very high value of $\mathrm{I}^{2}$ that can be interpreted that the population is very different and speaks of high heterogeneity. This interpretation is also a decision maker that a subgroup and moderator analysis must be conducted.

TABLE II: TEST OF HETEROGENEITY

\begin{tabular}{|l|l|}
\hline \multicolumn{2}{|l|}{ Heterogeneity } \\
\hline $\mathrm{Q}$ & 216.49 \\
\hline $\mathrm{p}_{\mathrm{Q}}$ & 0.000 \\
\hline $\mathrm{I}^{2}$ & $93.53 \%$ \\
\hline $\mathrm{T}^{2}$ & 0.51 \\
\hline $\mathrm{T}$ & 0.71 \\
\hline
\end{tabular}

\section{Subgroup Analysis}

\section{1) Subject matter}

Table III show a subgroup analysis of the subject matter Physics and Mathematics. As seen, the effect size of the two subgroups are nearly the same this only means that the two subgroups are very heterogeneous and hence cannot be meta-analyzed as if it is one single population [18]. Further, the two groups also has a very close weight which are $49.98 \%$ and $50.02 \%$ which denotes that the two groups can 
be analyzed separable.

TABLE III: SUBGROUP ANALYSIS FOR SUBJECT MATTER

\begin{tabular}{|l|c|c|c|}
\hline \multicolumn{1}{|c|}{ Subgroup } & $\mathrm{Q}$ & $\mathrm{pQ}$ & Weight \\
\hline Mathematics & $\mathbf{4 4 . 9 9}$ & $\mathbf{0 . 0 0 0}$ & $49.98 \%$ \\
\hline Physics & $\mathbf{1 2 6 . 1 6}$ & $\mathbf{0 . 0 0 0}$ & $\mathbf{5 0 . 0 2 \%}$ \\
\hline Combined Effect Size & $\mathbf{2 1 6 . 4 9}$ & $\mathbf{0 . 0 0 0}$ & \\
\hline
\end{tabular}

It can also be seen in Table III that the $\mathrm{p}$ value and the combined effect size of the subgroup Physics and Mathematics are both lower than 0.05 which has an interpretation that in a problem solving subjects like math and physics, Flipped Classroom has a positive effect on students' academic performance.

\section{2) Geographical location}

Table IV shows the subgroup analysis conducted under geographical location. For this purpose, regions in the world are divided into two hemisphere the eastern and western countries. It is seen in the data that both groups Eastern Countries and Western Countries has a p-value of 0.000 which is less than 0.005 which means that either side of the globe, east or west, the FCM has an effect to the academic performance of the students.

TABLE IV: SUBGROUP ANALYSIS FOR GEOGRAPHICAL LOCATION

\begin{tabular}{|l|c|c|c|}
\hline \multicolumn{1}{|c|}{ Subgroup } & Q & pQ & Weight \\
\hline $\begin{array}{l}\text { Eastern Part of the } \\
\text { Globe }\end{array}$ & $\mathbf{7 6 . 3 1}$ & $\mathbf{0 . 0 0 0}$ & $\mathbf{4 4 . 0 0 \%}$ \\
\hline $\begin{array}{l}\text { Western part of the } \\
\text { Globe }\end{array}$ & $\mathbf{6 6 . 0 1}$ & $\mathbf{0 . 0 0 0}$ & $\mathbf{5 6 . 0 0 \%}$ \\
\hline $\begin{array}{l}\text { Combined } \\
\text { Effect Size }\end{array}$ & $\mathbf{2 1 6 . 4 9}$ & $\mathbf{0 . 0 0 0}$ & \\
\hline
\end{tabular}

\section{E. Moderator Analysis}

\section{1) Implementation duration}

The purpose of this moderator analysis is to look at the duration of the implementation of the intervention if it affects the academic performance of the students. As presented in Table $\mathrm{V}$, the $\mathrm{p}$ value of the moderator, implementation duration, is 0.000 that means it has an effect on the academic performance of the students. It is reported by different studies that the longer the intervention was used by the students, the higher the effect of it to the academic performance of the students [4], and [32].

TABLE V: MODERATOR ANALYSIS FOR IMPLEMENTATION DURATION
\begin{tabular}{|l|l|l|l|l|}
\hline & CI LL & CI UL & Z-value & p-value \\
\hline Intercept & 1.79 & 4.13 & 5.65 & 0.000 \\
\hline Moderator & -0.28 & -0.07 & -3.67 & 0.000 \\
\hline
\end{tabular}

\section{2) Class size}

It is clearly seen in Table VI that the moderator, Class Size, has no significant effect in the effectiveness of the intervention Flipped Classroom Model which also supports the studies conducted by [19] and [33]. This can also possibly explained that in Flipped Classroom Model, instructions or content of the subject matter were given outside the class were students are given equal opportunity to learn the content without depending on the class size of the group.
TABLE VI: MODERATOR ANALYSIS FOR CLASS SIZE

\begin{tabular}{|l|l|l|l|l|}
\hline & CI LL & CI UL & Z-value & p-value \\
\hline Intercept & 0.49 & 2.18 & 3.41 & 0.001 \\
\hline Moderator & -0.02 & 0.00 & -1.19 & 0.233 \\
\hline
\end{tabular}

\section{Summary OF FindingS}

The meta-analysis conducted resulted to a report that the intervention, Flipped Classroom Model, has a high effect on the academic performance of the students with a p-value of 0.000 and has a Hegdes' $g$ value of 0.93 . This also means that Flipped Classroom Model outperformed the Traditional Lecture Model in enhancing students' academic performance in Physics and Mathematics.

The $\mathrm{p}$ value of the moderator implementation duration is 0.000 that means it has an effect on the academic performance of the students while the p-value of the moderator analysis on class size yields a 0.233 value that indicates class size has no significant effect in the academic performance of the students in Flipped Classroom model which also supports the studies conducted by [19]. This can also possibly explained that in Flipped Classroom Model, instructions were given outside the class were students are given equal opportunity to learn the content without depending on the class size of the group.

The subgroup analysis for both subject matter and geographical location yields an acceptable $p$ value which is interpreted that both in Physics and Math either the country is located in the eastern or western part of the globe, Flipped Classroom has a positive effect on students' academic performance.

\section{CONCLUSION}

FCM has been one of the widely utilized type of blended learning. Numbers of researches were conducted to compare FCM to traditional learning with academic achievement as a predictor variable of effectivity. This study meta-analyzed 15 articles to provide clarity in the comparison of FCM and traditional learning in improving students' academic achievement. As a whole, FCM was found to significantly improve academic achievement of students better than the traditional learning. Teachers can also maximize the effectiveness of FCM by prolonging the use of the intervention with the same set of students regardless of the class size. This is true in the subjects Physics and Mathematics either in the eastern and western part of the globe.

\section{EDUCATIONAL IMPLICATIONS}

This meta-analysis that is based on results of previous studies, favors the use of Flipped Classroom Model over Traditional Lecture Model in enhancing students' academic performance. It is true in subjects like Physics and Mathematics. FCM is also a possible solution to large class size since it was found by this study that regardless the class size, FCM enhances student's academic achievement. Location is not also a barrier with the use of FCM since the 
region where they are located does not give any significant difference in enhancing students' academic performance.

It is found that Flipped Classroom Model (FCM) has a high effect on the students' academic performance so educators and school administrators, especially during this time of pandemic, must consider FCM as a strategy to help students cope with the challenges that this new normal form of education has brought to us.

The use of FCM gets even more effective as the duration of implementation increases. The longer the students are subjected to the intervention, the better academic performance they manifest. Therefore, it is recommended to classroom teachers that the use of FCM is longitudinal.

Albalawi [21] and Aş1ksoy [22] mentioned that there is a need for a new technology that will fit the use of FCM. Sengel [25] and Sunday et al. [26] on the other hand finds the use of cooperative learning effective as accompaniment to FCM. This opens the possibility of further improvement in the use of the intervention.

There is a high demand in transitioning the mode of education from traditional to a student center type of education [14] and FCM is a solution to this [10], [14]. With this, school administrators must consider providing their teachers and students the facilities and technology needed in order to cope with the fast changing pace of education.

\section{CONFLICT OF INTEREST}

The authors declare no conflict of interest.

\section{AUTHOR CONTRIBUTIONS}

J.R. Sablan conducted the research, analyzed the data, and write the paper. M. Prudente supervised and give very insightful ideas throughout the conduct of the study.

\section{ACKNOWLEDGMENT}

The authors would like to thank the DOST SEI-CBPSME Scholarship for funding the publication of the paper and John Paul Eusebio for extensively reviewing all the pages of this manuscript for grammar checking.

\section{REFERENCES}

[1] M. Horn and H. Staker, The Rise of K-12 Blended Learning San Mateo, Innosight Institute, Inc.

[2] A. Barkley, "Flipping the college classroom for enhanced student learning," NACTA Journal, vol. 59, no. 3, pp. 240-244.

[3] K. Chung, L. Chi, and H. Khe, "Applying "first principles of instruction" as a design theory of the flipped classroom: Findings from a collective study of four secondary school subjects," Computers \& Education, vol. 118, 2018, pp. 150-165, ISSN 0360-1315.

[4] V. González, F. Ortega, J. Jiménez, and P. Molero, "Use of meditation and cognitive behavioral therapies for the treatment of stress, depression and anxiety in students. A systematic review and meta-analysis," International Journal of Environmental Research and Public Health, vol. 16, no. 22, p. 4394.

[5] J. Moore, R. Matthew, and D. Steele, "Fostering student engagement with the flip," The Mathematics Teacher, vol. 107, no. 6, pp. 420-425.

[6] J. Rafon and V. Mistades, "Interactive engagement in rotational motion via flipped classroom and 5e instructional model," International Journal of Information and Education Technology vol. 10, no. 12, pp. 905-910, 2020.

[7] C. Nwosisi, A. Ferreira, W. Rosenberg, and K. Walsh, "A study of the flipped classroom and its effectiveness in flipping thirty percent of the course content," International Journal of Information and Education Technology, vol. 6, no. 5, pp. 348-351, 2016.
[8] D. González, J. Jeong, D. Rodríguez, and F. Cañada, "Performance and perception in the flipped learning model: An initial approach to evaluate the effectiveness of a new teaching methodology in a general science classroom," Journal of Science Education and Technology, vol. 25, no. 3, pp. 450-459, August 3, 2020.

[9] M. Deri, P. Mills, and D. McGregor, "Structure and evaluation of a flipped general chemistry course as a model for small and large gateway science courses at an urban public institution," Journal of College Science Teaching, vol. 47, no. 3, pp. 68-77, August 3, 2020.

[10] I. M. Astra and S. I. Khumaeroh, "The effect of flipped classroom model on student's physics learning outcome in work and energy concept," Journal of Physics: Conference Series, vol. 1318, no. 1, 2019.

[11] A. Zandra, S. Otten, and S. Birisci, "Conceptualizing "homework" in flipped mathematics classes," Journal of Educational Technology \& Society, vol. 20, no, 1, pp. 248-260, August 3, 2020.

[12] B. J. B. Winter and M. State, "The effect of the flipped classroom model on achievement in an introductory college physics course," 2013.

[13] A. M. Al-Abdullatif, "Investigating self-regulated learning and academic achievement in an eLearning environment: The case of K-12 flipped classroom," Cogent Education, vol. 7, no. 1, 2020.

[14] J. Maholtra and J. Niranjan, "Quasi-experimental study on the effectiveness of a flipped classroom," Journal of the Gujarat Research Society, vol. 21, no. 11, pp. 550-554, ISSN: 0374-8588.

[15] J. Munawaroh, "The infuence of teaching methods and learning environment to the student's learning achievement of craft and entrepreneurship subjects at vocational high school," International Journal of Environmental \& Science Education, vol. 12, no. 4, pp. 665-678.

[16] M. Page, J. McKenzie, P. Bossuyt, I. Boutron, T. Hoffmann, and C. Mulrow, "The PRISMA 2020 statement: an updated guideline for reporting systematic reviews," Systematic Reviews, 2021, vol. 10, p. 89.

[17] A. Harzing. Publish or Perish. [Online]. Available: https://harzing.com/resources/publish-orperish

[18] T. Hak, R. Van, and R. Suurmond, "How to interpret results of meta-analysis," The Netherlands: Erasmus Rotterdam Institute of Management.

[19] Y. Shi, Y. Ma, J. MacLeod, J. Yang, and H. Harrison, "College students' cognitive learning outcomes in flipped classroom instruction: A meta-analysis of the empirical literature," Journal of Computers in Education.

[20] M. Peplow. Social Sciences sufer from severe publication bias. [Online]. Available: https://www.nature.com/news/socialsciences-sufer-from-severe-publi cation-bias 1.15787

[21] A. Albalawi," The effect of using flipped classroom in teaching calculus on students" achievement at University of Tabuk," International Journal of Research in Education and Science (IJRES), vol. 4, no. 1, pp. 198-207.

[22] G. Aşıksoy and Y. Sorakin, "The effects of clicker-aided flipped classroom model on learning achievement, physics anxiety and students' perceptions," International Online Journal of Education and Teaching (IOJET), vol. 5, no. 2, pp. 334-346.

[23] D. Files, "Instructional approach and mathematics achievement: An investigation of traditional, online, and flipped classrooms in college algebra (Order No. 10100739)," ProQuest Dissertations \& Theses $A \& I$.

[24] C. Quint, "A study of the efficacy of the flipped classroom model in a university mathematics class (Order No. 3707108)," ProQuest Dissertations \& Theses A\&I.

[25] D. Ronnebaum, "A comparison of course practices and student outcomes in traditional lecture versus modified flipped algebra I classrooms (Order No. 10821664)," ProQuest Dissertations \& Theses A\&I.

[26] D. C. D. Alten, C. Phielix, J. Janssen, and L. Kester, "Self-regulated learning support in flipped learning videos enhances learning outcomes," Computers and Education, p. 158, 2020.

[27] D. C. D. Alten, C. Phielix, J. Janssen, and L. Kester, "Effects of self-regulated learning prompts in a flipped history classroom," Computers in Human Behavior, vol. 108, 2020.

[28] G. Schiltz, G. Feldman, and A. Vaterlaus, "Flipping large university courses: How do student learning gains improve compared to lectures?" EDULEARN18 Proceedings, 2018.

[29] E. Şengel, "To FLIP or not to FLIP: Comparative case study in higher education in Turkey," Computers in Human Behavior, vol. 64, 2016, pp. $547-555$. 
[30] C. Sunday, N. Chukwuebuka, E. Ugochukwu, and O. Ngozi, "Effect of flipped classroom and think pair share strategy on achievement and retention among senior secondary school physics students," 2020.

[31] Y. T. Wei, Y. H. Shi et al., Blended Learning versus Traditional Learning: A Study on Students' Learning Achievements and Academic Press, pp. 219-223, 2017.

[32] Y. Kidron, and J. Lindsay, "The effects of increased learning time on student academic and nonacademic outcomes: Findings from a meta-analytic review (REL 2014-015)," Washington, DC: U.S Department of Education, Institute of Education Sciences, National Center for Education Evaluation and Regional Assistance, Regional Educational Laboratory Appalachia.

[33] G. Bas and O. Beyhan, "Revisiting the effect of teaching of learning strategies on academic achievement: A meta-analysis of the findings," International Journal of Research in Education and Science (IJRES), vol. 5, no. 1, pp. 70-87.

Copyright $\odot 2022$ by the authors. This is an open access article distributed under the Creative Commons Attribution License which permits unrestricted use, distribution, and reproduction in any medium, provided the original work is properly cited (CC BY 4.0).

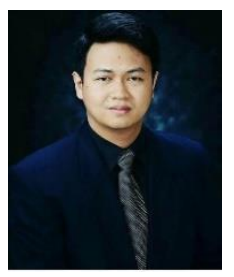

Jack Robert B. Sablan was born on August 19, 1994 in the small town of Angono in the province of Rizal, Philippines. He finished the master of arts in science education with highest distinction on year 2018 in Rizal Technological University, Mandaluyong City, Philippines, and is currently a doctorate student in the De La Salle University, Manila, for the degree, doctor of philosophy in science education with specialization in physics.

Since he graduated in college, he has been a college instructor in the College of Arts and Sciences in Rizal Technological University. He co-authored a book, Natural Science Series, Physical Science (Malabon City, Mutya Publishing House, Inc., 2019). His current research interests were on the use of flipped classroom model and development of video lectures that can maximize the potential of the use of FCM.
Prof. Sablan is a member of the National Geographic Society as a certified Integrated Service Learning teacher. He is also a regular member of the Philippine Association of Physics and Science Instructors (PAPSI). He also won the second place for best Research in the Research Colloquium for graduate School Category in Rizal Technological University held in year 2015.

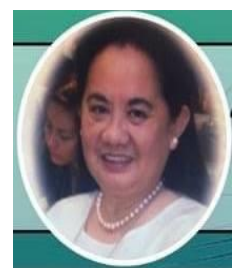

Maricar S. Prudente is presently a full professor of the Science Education Department at De La Salle University-Manila. Professor Prudente completed her $\mathrm{Ph} . \mathrm{D}$. in environmental chemistry and ecotoxicology at Ehime University, Japan under a Japan Society for the Promotion of Science (JSPS) Ronpaku Fellow Grant. As an educator, Dr. Prudente has served as administrator in various capacities at De La Salle University- Manila - as Academic Chairperson of the Science Education Department and as Research Director of the Lasallian Institute for Development and Educational Research (LIDER). Dr. Prudente has also served as a resource person, facilitator and coordinator in various seminars, workshops and training programs dealing with action research, environmental issues, science education, and technology integration. She is the Chairperson and Organizer of the Action Research Action Learning (ARAL) International Congress held annually at De La Salle University Manila.

She has authored and co-authored 56 scientific research papers published in ISI and Scopus-indexed journal and she has 35 research papers on science education and action research that were also published in peer-reviewed Scopus-indexed journals.

Prof. Prudente's involvement in research was recognized in 2015 when she was awarded the Lasallian Pillar of Excellence in Research by De La Salle University-Manila. In the same year, Dr. Prudente was the recipient of the 2015 Lifetime National Achievement Award of the National Research Council of the Philippines (NRCP). Moreover, Prof. Prudente was recently recognized as the 2018 Outstanding Filipino JSPS Fellow in the field of Education by the Department of Science and Technology (DOST) and the Japan Society for the Promotion of Science (JSPS). 